\title{
Diversity and community structure of harpacticoid copepods associated with cold-water coral substrates in the Porcupine Seabight (North-East Atlantic)
}

\author{
Hendrik Gheerardyn • Marleen De Troch • \\ Magda Vincx • Ann Vanreusel
}

Received: 12 March 2009 / Revised: 25 June 2009 / Accepted: 2 July 2009 / Published online: 1 August 2009

(C) Springer-Verlag and AWI 2009

\begin{abstract}
The influence of microhabitat type on the diversity and community structure of the harpacticoid copepod fauna associated with a cold-water coral degradation zone was investigated in the Porcupine Seabight (North-East Atlantic). Three substrate types were distinguished: dead fragments of the cold-water coral Lophelia pertusa, skeletons of the glass sponge Aphrocallistes bocagei and the underlying sediment. At the family level, it appears that coral fragments and underlying sediment do not harbour distinctly different assemblages, with Ectinosomatidae, Ameiridae, Pseudotachidiidae, Argestidae and Miraciidae as most abundant. Conclusions on assemblage structure and diversity of the sponge skeletons are limited as only two samples were available. Similarity analysis at species level showed a strong variation in the sediment samples, which did not harbour a distinctly different assemblage in opposition to the coral and sponge samples. Several factors (sediment infill on the hard substrates, mobility of the copepods, limited sample sizes) are proposed to explain this apparent lack of a distinct difference between the microhabitats. Coral fragments and sediment were both characterised by high species diversity and low species dominance, which might indicate that copepod diversity is not substantially influenced by hydrodynamical stress. The additive partitioning of species diversity showed that by adding locations species richness was greatly enhanced. The harpacticoid community in the cold-water coral degradation zone is
\end{abstract}

Communicated by H.-D. Franke.

H. Gheerardyn $(\varangle) \cdot$ M. De Troch $\cdot$ M. Vincx $\cdot$ A. Vanreusel

Marine Biology Section, Biology Department,

Ghent University, Campus Sterre - Building S8,

Krijgslaan 281, 9000 Ghent, Belgium

e-mail: hendrik.gheerardyn@ugent.be highly diverse and includes 157 species, 62 genera and 19 families. Information from neighbouring soft-bottom regions is necessary to assess whether total species diversity is increased by the presence of these complex habitatproviding substrates.

Keywords Cold-water corals · Biodiversity .

Microhabitats $\cdot$ Harpacticoid copepods .

North-East Atlantic $\cdot$ Porcupine Seabight

\section{Introduction}

Cold-water corals are arguably the most three-dimensionally complex habitats in the deep ocean, providing niches for many species (Roberts et al. 2006). Virtually all studies on cold-water coral reefs show that they sustain diverse macro- and megafaunal communities and that their biodiversity rivals the diversity of tropical zooxanthellate coral reefs (Rogers 1999; Henry and Roberts 2007; Roberts et al. 2008). Moreover, highest-diversity communities have been found within the dead and mixed live and dead coral framework of Lophelia pertusa (Linnaeus, 1758) reefs (Jensen and Frederiksen 1992; Mortensen et al. 1995; Freiwald et al. 2002). Potential explanations are that coral associates there find shelter and avoid being harmed or consumed by live coral polyps, the decreased competition with L. pertusa for suspended particles, or lower removal rates of larvae by L. pertusa (Cordes et al. 2008).

The associated metazoan meiofauna and nematofauna of L. pertusa reef degradation zones have recently been studied by Raes and Vanreusel $(2005,2006)$ in the Belgica Mound Province of the Porcupine Seabight (North-East Atlantic). Living coral is assumed not to be a suitable substrate for meiofauna, while the dead coral framework 
provides favourable surfaces especially for the meioepifauna. Raes and Vanreusel (2006) found significantly different nematode assemblages associated with dead coral fragments, glass sponge skeletons and underlying sediment, and physical disturbance by bottom currents, substrate type, sediment infill and food availability were proposed as important structuring factors.

Harpacticoid copepods are generally the second most abundant taxon after the numerical dominant Nematoda in the deep-sea meiobenthos, and become even more important on the hard biogenic substrates of the cold-water coral degradation zone (Raes and Vanreusel 2005). The present study therefore investigates the associated harpacticoids of these $L$. pertusa reef degradation zones in the Belgica Mound Province. The spatial heterogeneity of biologically produced structures has already been suggested to affect distribution patterns of deep-sea harpacticoid species (Thistle and Eckman 1990), and we will examine here the importance of the different microhabitats of the coral degradation zone (i.e. dead fragments of $L$. pertusa, skeletons of the glass sponge Aphrocallistes bocagei Schultze, 1886 and underlying sediment) in structuring harpacticoid community composition and diversity. Furthermore, as the coral degradation zone undoubtedly represents great habitat heterogeneity, we will assess whether total species diversity is higher there than in the surrounding soft-bottom deep sea. A detailed account of the species composition in this coral degradation zone has been presented by Gheerardyn et al. (2009).

\section{Materials and methods}

Study area and sampling procedure

The Porcupine Seabight is a large embayment in the continental margin to the south-west of Ireland (Fig. 1). Along the eastern margin of the basin partly buried and seabed coral banks represent the Belgica Mound Province, with many of the banks hosting living deep-water corals (mainly the framework builder Lophelia pertusa) and associated fauna (Henriet et al. 1998; De Mol et al. 2002). These coldwater corals are present only on the basinward flank of the mounds (De Mol et al. 2002). The upper slope $(<1000 \mathrm{~m})$ settings are subject to a complex hydrodynamic regime with interactions of tidal currents, vertical mixing, northward flow along the north-eastern continental slopes, internal tides and the effect of topography (De Mol 2002).

In the coral degradation zone from two seabed mounds in the Belgica Mound Province, six sites were sampled with a round boxcorer (developed by the Netherlands Institute for Sea Research, diameter $32 \mathrm{~cm}$ ) from RV Belgica (Table 1) and this yielded 6 sediment, 6 coral and 2 sponge samples. The material was collected at depths between 880 and $1005 \mathrm{~m}$, with boxes 3 and 4 taken between the two mounds and boxes 1, 2, 5 and 6 taken from the seamound flanks. In each case, the boxcorer penetrated $15-20 \mathrm{~cm}$ into the sediment (with the exception of Box 3, which penetrated $5 \mathrm{~cm}$ into the sediment). The surface of the sediment was partly or entirely covered with several dead fragments of the cold-water coral L. pertusa (and also skeletons of the glass sponge Aphrocallistes bocagei in Boxes 1 and 3). Aboard the research vessel, coral fragments and sponge skeletons were collected separately, after removal of the overlying water. Then, three cores (surface area $10 \mathrm{~cm}^{2}$ ) for collection of meiofauna were pushed into the underlying sediment of each boxcorer. An additional core $\left(10 \mathrm{~cm}^{2}\right)$ was collected for granulometric analysis. Three microhabitat types were defined in the samples from the coral degradation zone: (a) coral fragments, (b) sponge skeletons and (c) the underlying sediment (see Fig. 2 in Raes and Vanreusel 2005). The underlying sediment contained small fragments of both biogenic substrates, as well as some small mollusc
Fig. 1 Map of the Porcupine Seabight (NE Atlantic Ocean), and a detail showing the ridge of mounds in the Belgica Mound Province, with indication of the exact boxcorer locations. Multibeam bathymetry by courtesy of AWI Bremerhaven, contour interval at $10 \mathrm{~m}$

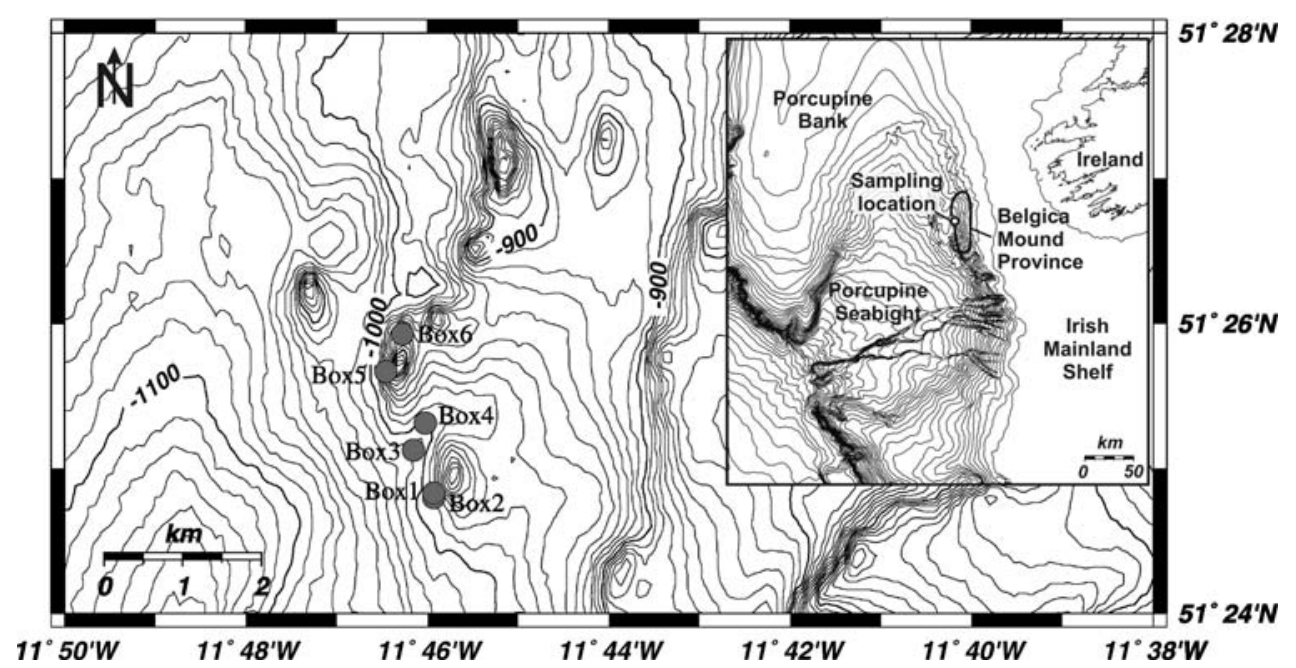


Table 1 Depth, date, geographical position, and microhabitats sampled per boxcorer taken at the Porcupine Seabight, with harpacticoid density (as individuals $/ 10 \mathrm{~cm}^{2} \pm \mathrm{SD}$ for sediment samples and individuals $/ 100 \mathrm{ml}$ for coral and sponge samples)

\begin{tabular}{|c|c|c|c|c|c|c|}
\hline \multirow[t]{2}{*}{ Boxcorer } & \multirow[t]{2}{*}{ Date } & \multicolumn{2}{|l|}{ Coordinates } & \multirow[t]{2}{*}{ Depth (m) } & \multirow[t]{2}{*}{ Sample } & \multirow{2}{*}{$\begin{array}{l}\text { Harpacticoid } \\
\text { density }\end{array}$} \\
\hline & & Latitude & Longitude & & & \\
\hline \multirow[t]{3}{*}{ Box 1} & 17.06 .2000 & $51^{\circ} 24.802^{\prime} \mathrm{N}$ & $11^{\circ} 45.924^{\prime} \mathrm{W}$ & 1,005 & sed1 & $19 \pm 7$ \\
\hline & & & & & cor 1 & 250 \\
\hline & & & & & spo1 & - \\
\hline \multirow[t]{2}{*}{ Box2 } & 17.06 .2000 & $51^{\circ} 24.824^{\prime} \mathrm{N}$ & $11^{\circ} 45.932^{\prime} \mathrm{W}$ & 1,000 & sed2 & $4 \pm 3$ \\
\hline & & & & & cor2 & 272 \\
\hline \multirow[t]{3}{*}{ Box3 } & 07.05 .2001 & $51^{\circ} 25.1290^{\prime} \mathrm{N}$ & $11^{\circ} 46.1553^{\prime} \mathrm{W}$ & 972 & $\operatorname{sed} 3$ & 26 \\
\hline & & & & & $\operatorname{cor} 3$ & 97 \\
\hline & & & & & spo3 & 207 \\
\hline \multirow[t]{2}{*}{ Box 4} & 07.05 .2001 & $51^{\circ} 25.3120^{\prime} \mathrm{N}$ & $11^{\circ} 46.0226^{\prime} \mathrm{W}$ & 969 & sed4 & 9 \\
\hline & & & & & cor 4 & 665 \\
\hline \multirow[t]{2}{*}{ Box 5} & 07.05 .2001 & $51^{\circ} 25.6700^{\prime} \mathrm{N}$ & $11^{\circ} 46.4553^{\prime} \mathrm{W}$ & 950 & sed5 & 4 \\
\hline & & & & & $\operatorname{cor} 5$ & 129 \\
\hline \multirow[t]{2}{*}{ Box6 } & 07.05 .2001 & $51^{\circ} 25.9290^{\prime} \mathrm{N}$ & $11^{\circ} 46.2717^{\prime} \mathrm{W}$ & 880 & sed6 & 27 \\
\hline & & & & & cor6 & 208 \\
\hline
\end{tabular}

Sed underlying sediment, cor coral fragment, spo sponge skeleton (in boxcorers 3 to 6 , the three sedimentcores per boxcorer were erroneously collected together)

Table 2 Granulometric characteristics of the underlying sediment at the coral degradation zone (data for box 1 and 2 are not available)

\begin{tabular}{lclll}
\hline & Clay $(\%)$ & Silt $(\%)$ & Sand $(\%)$ & $\begin{array}{l}\text { Median grain } \\
\text { size }(\mu \mathrm{m})\end{array}$ \\
\hline Box3 & 8.5 & 19.5 & 72.0 & 194.9 \\
Box4 & 32.7 & 47.3 & 20.0 & 8.3 \\
Box5 & 15.0 & 31.9 & 53.1 & 75.4 \\
Box6 & 19.7 & 34.2 & 46.1 & 46.0 \\
\hline
\end{tabular}

shells and echinoid radioles. The underlying sediment showed large variation in sediment texture (Table 2). It consisted mainly of fine to medium sand and a more or less pronounced silt fraction, with the median grain size ranging between $8.3-194.9 \mu \mathrm{m}$. All material was fixed with $4 \%$ buffered formaldehyde.

\section{Laboratory analyses}

In the laboratory, each coral or sponge sample was rinsed thoroughly over $1 \mathrm{~mm}$ and $32 \mu \mathrm{m}$ sieves to collect macroand meiofauna, respectively. Volumes of all examined biogenic substrates were measured by immersion, as a proxy for surface area. Meiofauna from the sediment was extracted by density gradient centrifugation, using Ludox HS40 (specific density 1.18) as a flotation medium (Heip et al. 1985). Because sample volumes of the different substrate types could not readily be compared, per sample the first 200 randomly encountered copepods (or all copepods when less than 200 were present) were picked out and mounted in glycerine. All adult harpacticoids were identified to species using Lang (1948, 1965), Huys et al. (1996), Boxshall and Halsey (2004) and original species descriptions. Assignment of species to genera and families was in accordance with recent literature. The systematic status of Pseudotachidiidae Lang, 1936 and Rhynchothalestridae Lang, 1948 follows Willen (2000), the status of Miraciidae Dana, 1846 follows Willen (2000, 2002), and the status of Idyanthidae Lang, 1944, Neobradyidae Olofsson, 1917, and Zosimidae Seifried, 2003 follows Seifried (2003).

Statistical analyses

The non-parametric procedures multidimensional scaling (MDS) two-dimensional plot and one-way and two-way crossed analysis of similarity (ANOSIM) were used to compare sample similarity based on species composition (Clarke and Gorley 2001). Per boxcorer, copepods from the three sedimentcores were pooled and treated as one sediment sample. Per sample, data were standardised to relative abundance data and square root transformed prior to analysis. MDS was produced based on Bray-Curtis similarities between samples, calculated using the PRIMER5 software (Clarke and Gorley 2001).

Parametric (ANOVA) analyses of variance were performed with STATISTICA6 software. Bartlett's and Cochran's test were used to verify homogeneity of the variances prior to analysis. Rarefaction curves (Sanders 1968), calculated using the methods of Hurlbert (1971), were used to compare species richness. The equitability of the copepod 
fauna was studied based on species' abundance distributions as k-dominance curves (Lambshead et al. 1983). The total species diversity $(\gamma$, as measured by species richness or a diversity index) found in a collection of samples can be additively partitioned into the average diversity within samples $(\alpha)$ and among samples $(\beta)$ (Crist et al. 2003). In the present study, $\beta$-diversity is subdivided into $\beta_{1}$-diversity which is due to the differences in microhabitat and $\beta_{2}$-diversity generated by the differences in sampling sites. Additive partitioning of species diversity, as expressed by the ShannonWiener index $\mathrm{H}^{\prime}$ and $\mathrm{N}_{0}$ (Hill 1973), was conducted with PARTITION software (Veech et al. 2002; Crist et al. 2003), including sediment and coral samples.

\section{Results}

In total, samples from the coral degradation zone yielded 1,648 copepods for identification (Table 3). Representatives of five of the nine copepod orders were found. Harpacticoida made up the bulk of the specimens $(>90 \%)$ and never occurred with less than $85 \%$ of relative abundance of total copepod density in any sample. The other copepod orders were found only sporadically: Calanoida, Misophrioida and Siphonostomatoida each constituted of less than $1 \%$ of the specimens (with 1, 4 and 12 individuals, respectively), Cyclopoida made up $7.6 \%$ (with 125 individuals). The present study focused on the order of Harpacticoida and, therefore, all other orders were left out of the analyses. Of the 1,506 harpacticoid copepods, 872 (or 58\%) were adults and 634 (or $42 \%$ ) were in the copepodid stage. Harpacticoid densities in the underlying sediment were very low (Table 1). Further analyses were based on adult harpacticoids, due to the impossibility of identifying most of the copepodids. Also, 12 damaged adults were left out because of identification problems.

Harpacticoid community composition

In total, 860 adult harpacticoids were determined to species level and this yielded 157 species, 62 genera and 19 families. Five families (Ectinosomatidae, Ameiridae, Pseudotachidiidae, Argestidae and Miraciidae) were abundant in each of the microhabitats (Table 4). Together, they represented $75.2 \%$ of relative abundance in the sediment and coral samples and $83.9 \%$ in the sponge samples. Each of these families did not differ significantly in relative abundance among the sediment and coral samples (ANOVA, $p>0.05$ ), but Pseudotachidiidae occurred with a distinctly higher relative abundance on the sponge skeletons. Ectinosomatidae was the dominant family in sediment and coral samples (24.8 and 29.6\%, respectively), while Pseudotachidiidae dominated in the sponge samples (31.0\%). The three microhabitats shared another five families (Canthocamptidae, Paramesochridae, Laophontidae, Harpacticidae and Neobradyidae), each representing between 0.7 and $5.6 \%$ in any of the microhabitats, and these did not differ significantly in relative abundance among the sediment and coral samples (ANOVA, $p>0.05$ ).

There were no distinctly dominant genera in the sediment or coral samples (Table 5). Pseudomesochra, Halophytophilus and Sigmatidium (and also Ameira and Pseudobradya in the coral samples) showed a relative abundance between 5 and $10 \%$. All other genera did not exceed $5 \%$ of relative abundance. On the sponge skeletons, Pseudomesochra and Ameira (with 31 and $12 \%$ of relative abundance,
Table 3 Total number of Copepoda, Harpacticoida, harpacticoid adults, number of species and average number of adults per species within each sample

Samples are ordered according to microhabitat (sed, cor, spo)

\begin{tabular}{lccccc}
\hline Sample & $\begin{array}{l}\text { Total } \\
\text { Copepoda }\end{array}$ & $\begin{array}{l}\text { Total } \\
\text { Harpacticoida }\end{array}$ & $\begin{array}{l}\text { Number of } \\
\text { harpacticoid adults }\end{array}$ & $\begin{array}{l}\text { Number } \\
\text { of species }\end{array}$ & $\begin{array}{l}\text { Average number } \\
\text { of adults per species }\end{array}$ \\
\hline sed1 & 62 & 56 & 30 & 21 & 1.4 \\
sed2 & 13 & 13 & 7 & 7 & 1.0 \\
sed3 & 85 & 79 & 34 & 24 & 1.4 \\
sed4 & 29 & 26 & 18 & 15 & 1.2 \\
sed5 & 13 & 13 & 7 & 6 & 1.2 \\
sed6 & 84 & 80 & 37 & 24 & 1.5 \\
cor1 & 200 & 185 & 97 & 47 & 2.1 \\
cor2 & 200 & 181 & 125 & 51 & 2.3 \\
cor3 & 136 & 122 & 78 & 37 & 2.1 \\
cor4 & 200 & 185 & 102 & 44 & 2.3 \\
cor5 & 103 & 93 & 68 & 35 & 1.9 \\
cor6 & 200 & 170 & 102 & 49 & 2.1 \\
spo1 & 123 & 114 & 67 & 34 & 2.0 \\
spo3 & 200 & 189 & 88 & 37 & 2.4 \\
Total dataset & 1,648 & 1,506 & 860 & 157 & 5.5 \\
\hline
\end{tabular}


Table 4 Harpacticoid family composition per microhabitat in the cold-water coral degradation zone, based on pooled samples per microhabitat

\begin{tabular}{lrcc}
\hline Family & $\begin{array}{l}\text { Underlying } \\
\text { sediment }(\%)\end{array}$ & $\begin{array}{l}\text { Coral } \\
\text { fragments }(\%)\end{array}$ & $\begin{array}{l}\text { Sponge } \\
\text { skeletons }(\%)\end{array}$ \\
\hline Ameiridae & 21.05 & 19.41 & 18.71 \\
Ancorabolidae & 0.75 & 1.40 & \\
Argestidae & 10.53 & 7.52 & 7.10 \\
Canthocamptidae & 4.51 & 5.59 & 1.94 \\
Cletodidae & 0.75 & & 0.65 \\
Ectinosomatidae & 24.81 & 29.55 & 21.29 \\
Harpacticidae & 2.26 & 3.15 & 3.87 \\
Huntemanniidae & 0.75 & 0.17 & \\
Idyanthidae & & 3.85 & 1.94 \\
Laophontidae & 3.01 & 3.85 & 2.58 \\
Miraciidae & 5.26 & 7.52 & 5.81 \\
Neobradyidae & 2.26 & 1.92 & 0.65 \\
Novocriniidae & & 0.70 & \\
Paramesochridae & 3.76 & 2.62 & 1.94 \\
Pseudotachidiidae & 13.53 & 11.19 & 30.97 \\
Rhynchothalestridae & & 0.87 & 1.29 \\
Tegastidae & & 0.17 & \\
Tetragonicipitidae & 3.76 & 0.17 & \\
Zosimidae & 2.26 & 0.35 & \\
Harpacticoida i.s. & 0.75 & & \\
\hline
\end{tabular}

respectively) were most abundant. Apart from Microsetella and Sigmatidium, all other genera had a relative abundance of less than 5\%. In the coral degradation zone, 21 genera (most of them belonging to Ectinosomatidae, Argestidae, Ameiridae and Miraciidae) were present in each of the three microhabitats. The genera restricted to one of the microhabitats $(6,14$ and 2 genera in sediment, coral and sponge samples, respectively) were found only sporadically and never exceeded $2.5 \%$ of relative abundance in their respective microhabitat. Also, any of the genera shared between sediment-coral (11), coral-sponge (7) and sediment-sponge (1) never exceeded $4 \%$ of relative abundance in any of the microhabitats.

Two species, Sigmatidium sp. 6 (Ectinosomatidae) and Pseudomesochra sp. 4 (Pseudotachidiidae), each accounted for 5\% of the total of adult individuals (Fig. 2). Twentyfour species each had a relative abundance between 1 and $4.5 \%$. The remaining 131 species each occurred with less than $1 \%$ of relative abundance and 52 species were present as singletons. The sediment, coral and sponge samples yielded 74, 121 and 54 species, respectively. One species in the sediment exceeded $5 \%$ of relative abundance (Halophytophilus lopheliae at 5.3\%). Two species exceeded 5\% of relative abundance in the coral samples (Pseudobradya cf. banyulensis at $6.1 \%$ and Sigmatidium sp. 6 at 5.9\%).
Table 5 Harpacticoid genera (with a relative abundance of minimum $2 \%$ in at least one microhabitat) from the cold-water coral degradation zone, per microhabitat

\begin{tabular}{|c|c|c|c|}
\hline Genus & $\begin{array}{l}\text { Underlying } \\
\text { sediment }(\%)\end{array}$ & $\begin{array}{l}\text { Coral } \\
\text { fragments }(\%)\end{array}$ & $\begin{array}{l}\text { Sponge } \\
\text { skeletons }(\%)\end{array}$ \\
\hline Ameira & 3.01 & 8.22 & 11.61 \\
\hline Amphiascus & 3.76 & 3.67 & 4.52 \\
\hline Bradya & 2.26 & 0.70 & 1.29 \\
\hline Dizahavia & 2.26 & 0.52 & 1.94 \\
\hline Ectinosoma & 1.50 & 2.10 & 0.65 \\
\hline Eurycletodes & 0.75 & 0.52 & 2.58 \\
\hline Filexilia & 2.26 & & \\
\hline Fultonia & 0.75 & 3.85 & \\
\hline Halophytophilus & 7.52 & 5.24 & 2.58 \\
\hline Idyanthe & & 2.62 & 1.94 \\
\hline Klieosoma & 1.50 & 1.57 & 3.23 \\
\hline Laophonte & 2.26 & 3.67 & 2.58 \\
\hline Leptomesochra & 4.51 & 1.40 & 2.58 \\
\hline Leptopsyllus & 2.26 & 0.52 & \\
\hline Mesocletodes & 3.76 & 0.35 & \\
\hline Microsetella & 0.75 & 0.87 & 6.45 \\
\hline Neobradyidae gen. 1 & 2.26 & 0.52 & \\
\hline Perissocope & 2.26 & 3.15 & 3.87 \\
\hline Pseudameira & 3.76 & 0.70 & \\
\hline Pseudobradya & 3.76 & 8.04 & 0.65 \\
\hline Pseudomesochra & 9.02 & 8.22 & 30.97 \\
\hline Sarsameira & 0.75 & 3.15 & 0.65 \\
\hline Sigmatidium & 6.02 & 9.97 & 5.81 \\
\hline Stenocopia & 2.26 & 1.75 & 0.65 \\
\hline $\begin{array}{l}\text { Tetragonicipitidae } \\
\text { gen. } 1\end{array}$ & 3.76 & 0.17 & \\
\hline Xylora & 3.01 & 1.40 & \\
\hline Zosime & 2.26 & 0.35 & \\
\hline $\begin{array}{l}\text { Total number } \\
\text { of genera }\end{array}$ & 47 & 67 & 36 \\
\hline
\end{tabular}

Two species of Pseudomesochra were relatively abundant (Pseudomesochra sp. 1 with $13.6 \%$ and Pseudomesochra sp. 4 with $8.4 \%$ ) in the sponge samples.

Similarity analysis

The MDS graph at species level showed that coral samples were clustered and sediment samples widely scattered around (Fig. 3). Pairwise comparison of the substrate groups with one-way ANOSIM was only significant for sediment-coral $(p=0.004)$ and showed these microhabitats as barely separable $(R=0.231)$. One-way ANOSIM comparing infauna (sediment samples) and epifauna (pooled coral and sponge samples) showed these groups also overlapping but slightly more separable $(R=0.405 ; p=0.003)$. 


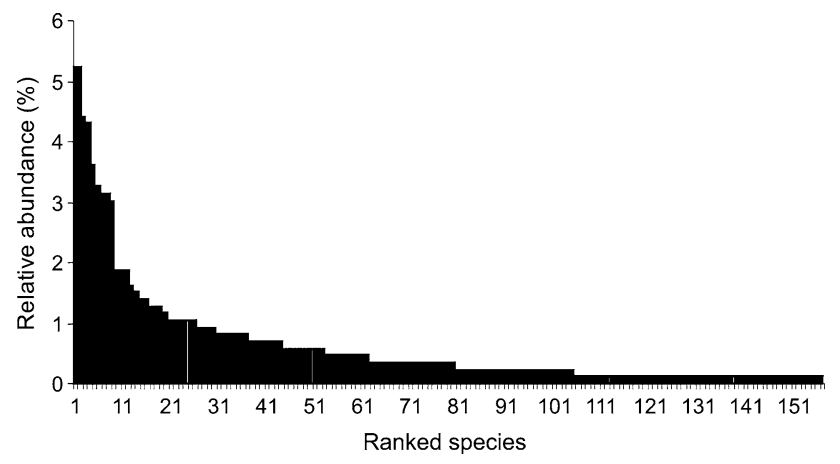

Fig. 2 Rank-order of abundance histogram. The height of the bar for each species represents its relative abundance when all samples are pooled

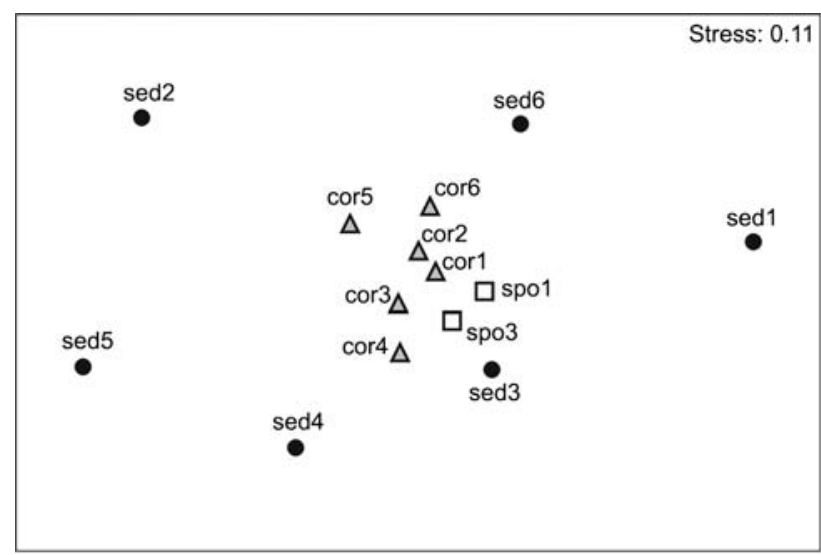

- Underlying sediment $\Delta$ Coral fragments $\square$ Sponge skeletons

Fig. 3 Multidimensional scaling (MDS) two-dimensional ordination plot. Stress value is indicated

The average dissimilarity in composition between infauna and epifauna is high $(82.1 \%)$ and mainly attributable to the higher abundance of Ameira sp. 1, Pseudomesochra sp. 4 and Pseudobradya cf. banyulensis (explaining 2.5, 2.3 and $2.3 \%$ of the dissimilarity, respectively) on the (pooled) coral and sponge samples and the higher abundance of Sigmatidium sp. 6 and Halophytophilus lopheliae (explaining

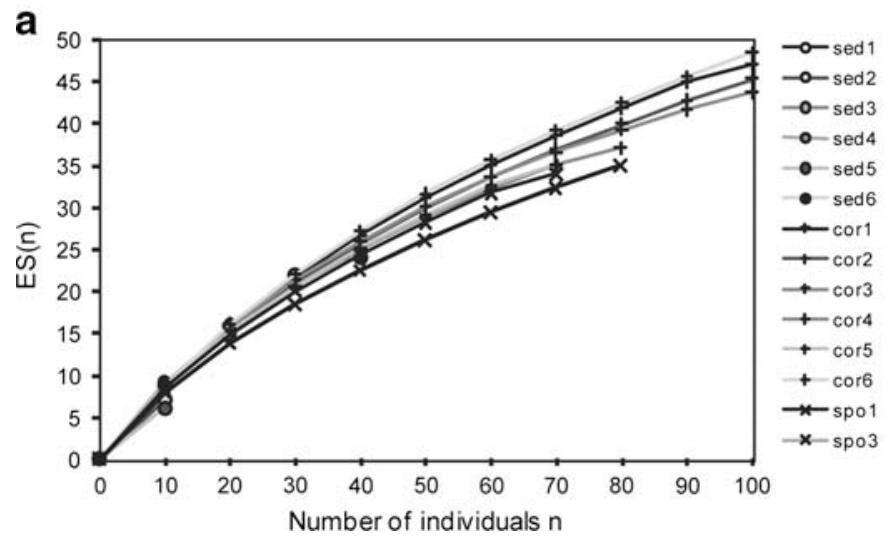

2.3 and $2.0 \%$ of the dissimilarity, respectively) in the underlying sediment (SIMPER). However, similarity within (pooled) coral and sponge samples (36.9\%) and within sediment samples (10.2\%) is rather low. Two-way crossed ANOSIM (including sediment and coral samples) showed no significant effect of the locations of the boxcorers (on the mound flank or in the channel between the mounds).

Diversity analysis

Rarefaction curves of the separate sediment and coral samples coincided and had a similar slope (Fig. 4a). The mean value $( \pm \mathrm{SD})$ of ES (50) for coral and sponge samples was $30.1 \pm 1.0$ and $27.1 \pm 1.0$, respectively. Rarefaction curves of the pooled data per substrate (Fig. $4 \mathrm{~b}$ ) showed a different pattern in which sediment had the highest diversity. K-dominance curves of the separate samples (Fig. 5a) all represented high equitability. K-dominance curves of the pooled data (Fig. 5b) showed that dominance in the sponge samples was slightly higher than in coral and sediment samples.

Additive partitioning of diversity (Fig. 6) indicated that total species richness $(\gamma)$ of the coral degradation zone was mainly attributed to differences between sampling sites $\left(\beta_{2}, 63.4 \%\right)$. Average diversity within microhabitats $(\alpha)$ and $\beta$-diversity due to turnover between microhabitats $\left(\beta_{1}\right)$ contributed 27.4 and $9.2 \%$, respectively. In contrast, $75.7 \%$ of the Shannon index was explained by $\alpha$-diversity, while $\beta_{1}$-diversity and $\beta_{2}$-diversity contributed less (7.0 and $17.3 \%$, respectively).

\section{Discussion}

The hard substrates examined here prevented the use of multiple corer, which is considered the best device available for sampling of open-sea, soft-bottom sediments (Bett

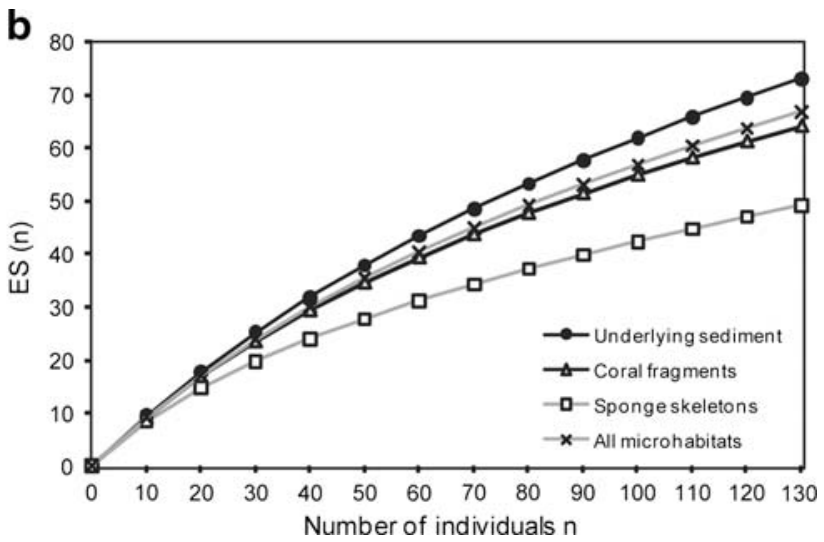

Fig. 4 Rarefaction curves $\mathbf{a}$ of all separate samples and $\mathbf{b}$ for the pooled data per microhabitat 

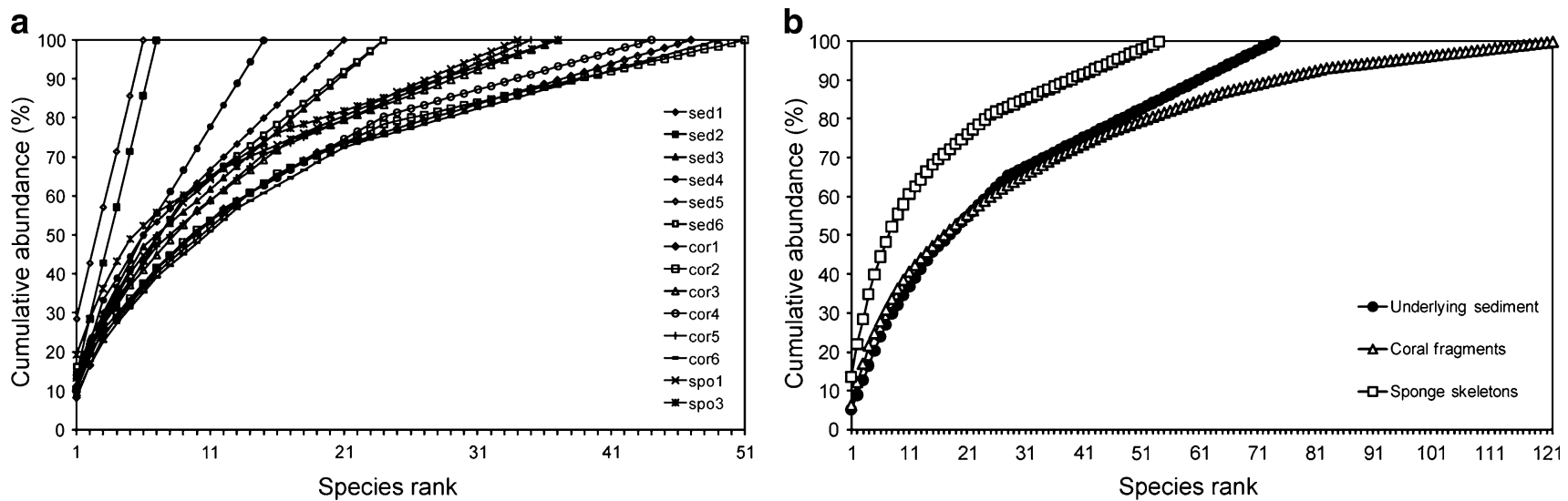

Fig. 5 K-dominance curves $\mathbf{a}$ of all separate samples and $\mathbf{b}$ for the pooled data per microhabitat

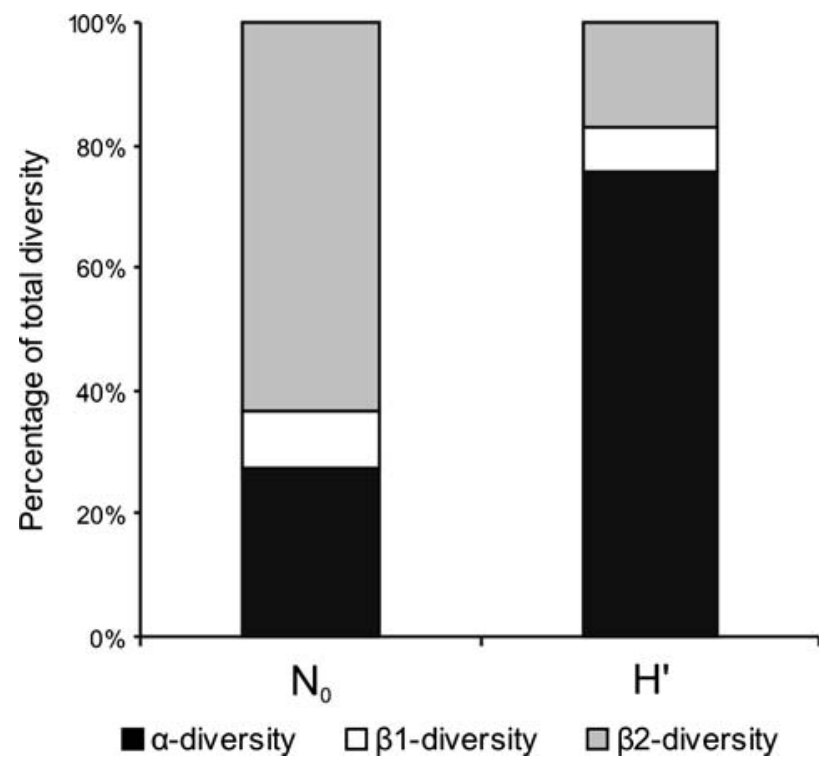

Fig. 6 Additive partitioning of total diversity for species richness $\mathrm{N}_{0}$ and Shannon-Wiener diversity $\mathrm{H}^{\prime}$. $\beta$ 1-diversity is the fraction of $\beta$-diversity due to the differences in microhabitat. $\beta 2$-diversity is the fraction of $\beta$-diversity due to the differences in localities

et al. 1994; Shirayama and Fukushima 1995). In the present study, the boxcorer may have caused sampling bias by washing away loose, light material containing associated fauna and also disturbance by its intrusion through the coral fragments. Considering this, we must be careful in interpreting trends in community structure and diversity based on these boxcorer samples. Nevertheless, the observed abundances in the underlying sediment are of a same order of magnitude as those found at a comparable depth along the nearby northwestern slope of the Porcupine Seabight $\left(33 \pm 15\right.$ harpacticoids $/ 10 \mathrm{~cm}^{2}$ at $960 \mathrm{~m}$ depth, with multiple corer) by Pfannkuche (1985). Strict comparison with densities on the coral fragments and sponge skeletons was impossible because the exact surface area of these substrates had not been defined.
Harpacticoid copepod composition and microhabitat preferences

Although nature and structure of the examined microhabitats are different and the associated faunas likely experience different conditions (e.g. in terms of food supply and physical disturbance) (Raes and Vanreusel 2006), it appears that coral fragments and underlying sediment do not harbour distinctly different harpacticoid assemblages at family level. Five families (Ectinosomatidae, Ameiridae, Pseudotachidiidae, Argestidae and Miraciidae) were clearly abundant in each of the microhabitats. The high abundance of Pseudotachidiidae, and specifically of the mainly deepsea genus Pseudomesochra, on the sponge skeletons might indicate a preference for this substrate, although the described species of this genus have before been reported exclusively in or on muddy sediments (Willen 1996; Vasconcelos et al. 2008). However, conclusions on the fauna of the sponge skeletons are limited as only two samples were collected. Similarity analysis at species level showed that sediment and (pooled) coral and sponge samples are separable to a limited degree. However, there is strong variation in the composition of the sediment samples, which clearly do not form a clustered group in opposition to the coral and sponge samples. This large variation might be attributed to the low number of individuals collected from the sediment samples, and also to the variation in sediment granulometry.

Especially in the inter- and subtidal, it has been shown that harpacticoids form remarkably specific associations (at familial, and in many cases also at generic and specific level) with particular habitat types (Hicks and Coull 1983). In the present study, there were only slight indications that certain taxa show a preference for a particular substrate. For example, the new species of Tetragonicipitidae, a family known as characteristic in every coarse shell-gravel assemblage (Hicks and Coull 1983), had a distinctly higher abundance in the 
underlying sediment. Representatives of Ameira and Pseudobradya seemed to show a preference for the (pooled) coral and sponge samples, although these genera are present in most marine habitats (Hicks and Coull 1983). Halophytophilus lopheliae appeared to show a preference for the underlying sediment. However, Halophytophilus and three other ectinosomatid genera with prehensile first legs found in the coral degradation zone (Bradyellopsis, Klieosoma and Peltobradya) generally do not occur in samples of the soft-bottom deep-sea floor (Gheerardyn et al. 2008). Their presence in the deep sea is exceptional and most likely due to the occurrence of the hard substrates of the coral degradation zone. It is conceivable that the prehensile first legs in these taxa permit an epifaunal life style on the hard biogenic substrata (Gheerardyn et al. 2008). Several factors might be responsible in explaining this apparent lack of a distinct difference between the microhabitats. The sediment infill between the coral branches and on the sponge skeletons could attract typical sediment-dwellers, which obscure the presence of true epifaunal taxa. Furthermore, close contact between the upper sediment layer and the overlying epibenthic structure can facilitate exchange of the highly mobile harpacticoids. Copepods typically reside in the upper sediment layers, and many are good swimmers capable of active emergence (Palmer 1988; Walters and Bell 1994; Thistle 2003), a behaviour which has been shown to exist in the deep sea (Thistle et al. 2007). However, high evenness in combination with the limited sample sizes may also be important in explaining the apparent lack of distinctly different assemblages. In deep-sea studies, it is a common problem that low animal abundance and high diversity make it difficult to detect spatial changes in community structure, and this is conceivably an important factor here as well. Nevertheless, as discussed by Gheerardyn et al. (2009), the presence of certain, typically epifaunal taxa indicates that the hard substrates of the coral degradation zone provide an exceptional habitat in the soft-bottom deep sea.

\section{Harpacticoid diversity in the coral degradation zone}

The harpacticoid community in the coral degradation zone of the Porcupine Seabight is highly diverse. We identified 157 species, 62 genera and 19 families from 860 individuals, which means that a different species is encountered in one out of every five individuals. Harpacticoids in the deep sea are characterised by high species diversity and low species dominance (Seifried 2004; Rose et al. 2005), and the assemblage in the Porcupine Seabight forms no exception to this. Even more, the value of ES (50) over the complete dataset of the coral degradation zone is 35.3 , which is higher than reported values from deep-sea harpacticoid studies at western Atlantic (bathyal sites between Cape Lookout and Bermuda), eastern Pacific (Fieberling Guyot and San Diego Trough) and western Pacific (Sagami Bay) sites (Thistle 1978, 1998; Shimanaga et al. 2004; summarised in Shimanaga et al. (2004)). Contrary herewith, species diversity agrees well with values at comparable depths in the northern Gulf of Mexico (see Fig. 3 in Baguley et al. 2006; ES (30) in the Porcupine Seabight is 23.9). Comparison with values from these studies is, however, restricted because of the geographical and bathymetrical distance between the study sites, and differences in sampling procedure. The coral degradation zone undoubtedly provides a structurally more complex environment than normally encountered in the soft-bottom deep sea. At the moment, it is, however, difficult to assess the influence of this increased habitat complexity on total harpacticoid species diversity, because studies from nearby soft-bottom locations at similar depths are not available.

For the associated nematofauna, Raes and Vanreusel (2006) found that the community in the underlying sediment is significantly more diverse than on the coral fragments and sponge skeletons. They attributed this to increased habitat complexity and heterogeneity of the sediment (due to the presence of small biogenic structures), and higher disturbance by current activity for nematodes on both biogenic substrata. For the associated harpacticoids, it seems that the faunas of both underlying sediment and coral fragments are diverse and do not differ distinctly in terms of evenness. Thistle (1983) provided some evidence that differences in hydrodynamics may be less important for copepod diversity, which would explain this observation. However, because all rarefaction curves tend to converge at low abundances, no distinction between different richness patterns can be drawn if sample sizes are not sufficient (Tipper 1979) and this was likely to be the case with the sediment samples (none contained more than 50 adults). Furthermore, the observation of highest species richness in the underlying sediment (when samples are pooled according to microhabitat) should not be treated as conclusive, because pooling of replicates obscures the actual relationship between number of species and individuals at the sampling scale, and differences in heterogeneity among sites may then contribute to variation in diversity (Levin et al. 2001). The additive partitioning of species diversity showed that by adding locations species richness was greatly enhanced. The Shannon index showed these species to be rare, as most of the diversity was explained by $\alpha$, which means that the same 'common' species occurred across the different locations. $\beta$-diversity, due to differences in microhabitat, was rather small as expressed by both measures.

\section{Conclusion}

Trends in species composition and diversity of the harpacticoids associated with different substrate types in the coral 
degradation zone were difficult to assess, mainly because of the rather small size of the sediment samples and the low number of sponge samples. However, first conclusions are that harpacticoid composition and diversity are not distinctly different between coral fragments and underlying sediment. These observations contrast with those of the associated nematofauna, for which distinctly different assemblages on the three microhabitats and clearly different trends in diversity between sediment and overlying biogenic substrates were found (Raes and Vanreusel 2006). Future samplings should focus on the difference between the harpacticoid fauna on cold-water coral mounds and the adjacent off-mound soft-bottom habitat, and take environmental characteristics, the exact surface area and habitat complexity of the biogenic substrates and the amount of sediment infill into account. Still, this study indicates that the substrates of the coral degradation zone sustain a harpacticoid fauna with high species diversity and low species dominance.

Acknowledgments The authors want to thank Guy De Smet, Dr. Maarten Raes and Dr. Véronique Vanquickelberghe (Ghent University) for their sampling efforts and Bart Beuselinck, Danielle Schram and Annick Van Kenhove (Ghent University) for meiofauna extraction and granulometric analysis. The first and second authors acknowledge postdoctoral research grants from the Special Research Fund (Ghent University, BOF) and from the Fund for Scientific Research (FWOVlaanderen), respectively. This research was conducted within the framework of the HERMIONE project (EC Seventh Framework Research Programme), the national FWO Research Project G.0199.03 'A Comparative Study of the Meio-Epifauna Associated with Tropical and Cold-Water Coral Reefs', the UGent-BOF-GOA research project 01GZ0705 'Biogeography and Biodiversity of the Sea' and the MarBEF Network of Excellence 'Marine Biodiversity and Ecosystem Functioning', which is funded by the Sustainable Development, Global Change and Ecosystems Programme of the European Community's Sixth Framework Programme (contract no. GOCE-CT-2003-505446). Prof. Dr. Jean-Pierre Henriet and co-workers from the Renard Centre of Marine Geology, as well as the crew of the R.V. Belgica, are acknowledged for a successful collaboration. Dr. D. Van Rooij is kindly thanked for making the map of the Porcupine Seabight.

\section{References}

Baguley JG, Montagna PA, Lee W, Hyde LJ, Rowe GT (2006) Spatial and bathymetric trends in Harpacticoida (Copepoda) community structure in the northern Gulf of Mexico deep-sea. J Exp Mar Biol Ecol 330:327-341

Bett JB, Vanreusel A, Vincx M, Soltwedel T, Pfannkuche O, Lambshead PJD, Gooday AJ, Ferrero T, Dinet A (1994) Sampler bias in the quantitative study of deep-sea meiobenthos. Mar Ecol Prog Ser 104:197-203

Boxshall GA, Halsey SH (2004) Copepod orders and families. An introduction to Copepod diversity. Ray Society, London

Clarke KR, Gorley RN (2001) PRIMER v5: User Manual/Tutorial. PRIMER-E, Plymouth

Cordes EE, McGinley MP, Podowski EL, Becker EL, Lessard-Pilon S, Viada ST, Fisher CR (2008) Coral communities of the deep Gulf of Mexico. Deep-Sea Res Part I 55:777-787
Crist TO, Veech JA, Gering JC, Summerville KS (2003) Partitioning species diversity across landscapes and regions: a hierarchical analysis of $\alpha, \beta$, and $\gamma$ diversity. Am Nat 162:734-743

De Mol B (2002) Development of coral banks in Porcupine Seabight (SW Ireland): a multidisciplinary approach. PhD dissertation, Ghent University

De Mol B, Van Rensbergen P, Pillen S, Van Herreweghe K, Van Rooij D, McDonnell A, Huvenne V, Ivanov M, Swennen R, Henriet JP (2002) Large deep-water coral banks in the Porcupine Basin, southwest of Ireland. Mar Geol 188:193-231

Freiwald A, Hühnerbach V, Lindberg B, Wilson JB, Campbell J (2002) The Sula Reef complex, Norwegian shelf. Facies 47:179-200

Gheerardyn H, De Troch M, Vincx M, Vanreusel A (2009) Harpacticoida (Crustacea: Copepoda) associated with cold-water coral substrates in the Porcupine Seabight (NE Atlantic): species composition, diversity and reflections on the origin of the fauna. Sci Mar (in press)

Gheerardyn H, Seifried S, Vanreusel A (2008) A new species of Halophytophilus Brian, 1919 (Copepoda: Harpacticoida: Ectinosomatidae) from cold-water corals in the Porcupine Seabight (NE Atlantic). Zootaxa 1761:1-16

Heip C, Vincx M, Vranken G (1985) The ecology of marine nematodes. Oceanogr Mar Biol Annu Rev 23:399-489

Henriet JP, De Mol B, Pillen S, Vanneste M, Van Rooij D, Versteeg W, Croker PF, Shannon PM, Unnithan V, Bouriak S, Chachkine $P$ (1998) Gas hydrate crystals may help build reefs. Nature (Lond) 391:648-649

Henry L-A, Roberts JM (2007) Biodiversity and ecological composition of macrobenthos on cold-water coral mounds and adjacent off-mound habitat in the bathyal Porcupine Seabight, NE Atlantic. Deep-Sea Res Part I 54:654-672

Hicks GRF, Coull BC (1983) The ecology of marine meiobenthic harpacticoid copepods. Oceanogr Mar Biol Annu Rev 21:67-175

Hill MO (1973) Diversity and evenness: a unifying notation and its consequences. Ecology 54:427-432

Hurlbert SH (1971) The nonconcept of species diversity: a critique and alternative parameters. Ecology 52:577-586

Huys R, Gee JM, Moore CG, Hamond R (1996) Marine and brackish water harpacticoid copepods. Part 1. Synopses of the British Fauna (New Series), vol 51. Field Studies Council, Shrewsbury

Jensen A, Frederiksen R (1992) The fauna associated with the bankforming deepwater coral Lophelia pertusa (scleractinaria) on the Faroe shelf. Sarsia 77:53-69

Lambshead PJD, Platt HM, Shaw KM (1983) The detection of differences among assemblages of marine benthic species based on an assessment of dominance and diversity. J Nat Hist 17:859-874

Lang K (1948) Monographie der Harpacticiden, I \& II. Håkan Ohlssons Boktryckeri, Lund

Lang K (1965) Copepoda Harpacticoidea from the Californian Pacific coast. Kungl Svenska Vetensk Akad Hand 10:1-560

Levin LA, Etter RE, Rex MA, Gooday AJ, Smith CR, Pineda J, Stuart CT, Hessler RR, Pawson D (2001) Environmental influences on regional deep-sea species diversity. Annu Rev Ecol Syst 32:5193

Mortensen PB, Hovland M, Brattegard T, Farestveit R (1995) Deep water bioherms of the scleractinian coral Lophelia pertusa (L.) at $64^{\circ} \mathrm{N}$ on the Norwegian shelf: structure and associated megafauna. Sarsia 80:145-158

Palmer MA (1988) Dispersal of marine meiofauna: a review and conceptual model explaining passive transport and active emergence with implications for recruitment. Mar Ecol Prog Ser 48:81-91

Pfannkuche O (1985) The deep-sea meiofauna of the Porcupine Seabight and abyssal plain (NE Atlantic): population structure, distribution, standing stocks. Oceanol Acta 8:343-353

Raes M, Vanreusel A (2005) The metazoan meiofauna associated with a coldwater coral degradation zone in the Porcupine Seabight (NE 
Atlantic). In: Freiwald A, Roberts JM (eds) Cold-water corals and ecosystems. Springer, Berlin Heidelberg, pp 821-847

Raes M, Vanreusel A (2006) Microhabitat type determines the composition of nematode communities associated with sedimentclogged cold-water coral framework in the Porcupine Seabight (NE Atlantic). Deep-Sea Res Part I 53:1880-1894

Roberts JM, Wheeler AJ, Freiwald A (2006) Reefs of the deep: the biology and geology of cold-water coral ecosystems. Science 312:543-547

Roberts JM, Henry L-A, Long D, Hartley JP (2008) Cold-water coral reef frameworks, megafaunal communities and evidence for coral carbonate mounds on the Hatton Bank, north east Atlantic. Facies 54:297-316

Rogers AD (1999) The biology of Lophelia pertusa (Linnaeus 1785) and other deep-water reef-forming corals and impacts from human activities. Internat Rev Hydrobiol 84:315-406

Rose A, Seifried S, Willen E, George KH, Veit-Köhler G, Bröhldick K, Drewes J, Moura G, Martínez Arbizu P, Schminke HK (2005) A method for comparing within-core alpha diversity values from repeated multicorer samplings, shown for abyssal Harpacticoida (Crustacea: Copepoda) from the Angola Basin. Org Divers Evol $5: 3-17$

Sanders HL (1968) Marine benthic diversity: a comparative study. Am Nat 102:243-282

Seifried S (2003) Phylogeny of Harpacticoida (Copepoda): revision of "Maxillipedasphalea" and Exanechentra. Cuvillier, Göttingen

Seifried S (2004) The importance of a phylogenetic system for the study of deep-sea harpacticoid diversity. Zool Stud 43:435-445

Shimanaga M, Kitazato H, Shirayama Y (2004) Temporal patterns in diversity and species composition of deep-sea benthic copepods in bathyal Sagami Bay, central Japan. Mar Biol 144:1097-1110

Shirayama Y, Fukushima T (1995) Comparisons of deep-sea sediments and overlying water collected using multiple corer and box corer. J Oceanogr 51:75-82

Thistle D (1978) Harpacticoid dispersion patterns: implications for deep-sea diversity maintenance. J Mar Res 36:377-397
Thistle D (1983) The stability-time hypothesis as a predictor of diversity in deep-sea soft-bottom communities: a test. Deep-Sea Res 30:267-277

Thistle D (1998) Harpacticoid copepod diversity at two physically reworked sites in the deep sea. Deep-Dea Res 45:13-24

Thistle D (2003) Harpacticoid copepod emergence at a shelf site in summer and winter: implications for hydrodynamic and mating hypotheses. Mar Ecol Prog Ser 248:177-185

Thistle D, Eckman JE (1990) The effect of a biologically produced structure on the benthic copepods of a deep-sea site. Deep-Sea Res Part I 37:541-554

Thistle D, Sedlacek L, Carman KR, Fleeger JW, Barry JP (2007) Emergence in the deep sea: evidence from harpacticoid copepods. Deep-Sea Res Part I 54:1008-1014

Tipper JC (1979) Rarefaction and rarefiction - the use and abuse of a method in paleoecology. Paleobiology 5:423-434

Vasconcelos DM, George KH, Santos PJP (2008) First record of the genus Pseudomesochra T. Scott (Harpacticoida: Pseudotachidiidae) in the South Atlantic with description of a deep-sea species: Pseudomesochra longiseta sp. nov. Zootaxa 1866:337-348

Veech JA, Summerville KS, Crist TO, Gering JC (2002) The additive partitioning of species diversity: recent revival of an old idea. Oikos 99:3-9

Walters DG, Bell SS (1994) Significance of copepod emergence to benthic, pelagic and phytal linkages in a subtidal seagrass bed. Mar Ecol Prog Ser 108:237-249

Willen E (1996) Pseudomesochra T. Scott 1902 as a member of the Paranannopidae Por 1986 (Copepoda, Harpacticoida) with a description of three new species. Senckenb Marit 28:81-109

Willen E (2000) Phylogeny of the Thalestridimorpha Lang, 1944 (Crustacea, Copepoda). Cuvillier, Göttingen

Willen E (2002) Notes on the systematic position of the Stenheliinae (Copepoda, Harpacticoida) within the Thalestridimorpha and description of two new species from Motupore Island, Papua New Guinea. Cah Biol Mar 43:27-42 